\title{
A política nacional de uso de biodiesel - O direito como instrumento de promoção do desenvolvimento sustentável
}

\author{
Fernando do Rego Barros Filho* \\ Advogado. Assessor Jurídico junto ao Tribunal de Contas do Estado do Paraná. Especialista em \\ Direito Ambiental e Desenvolvimento pela Universidade Estadual do Amazonas (UEA).
}

\begin{abstract}
Resumo: Este trabalho possui o objetivo de avaliar a influência do Direito na formulação de políticas ambientais que possam direcionar as atividades econômicas e fornecer uma melhor qualidade à população. Os estudos são baseados nos parâmetros determinados na Política Nacional de Produção e Uso de Biodiesel (PNPB), que fornecem vários tópicos de discussão relativos à relação entre o Direito e a proteção do meio ambiente. A conclusão revela que a política ambiental necessita de determinações jurídicas que estimulem um contexto econômico, político e social direcionado a uma nova racionalidade de desenvolvimento, assim como a construção de uma cultura de efetivação das normas propostas.
\end{abstract}

Palavras-chave: Direito. Energia. Desenvolvimento social. Sustentabilidade.

Sumário: 1 Introdução - 2 Desenvolvimento social como integrante do conceito de desenvolvimento sustentável - 2.1 Direito ao meio ambiente ecologicamente equilibrado - 2.2 Desenvolvimento social como consequência do desenvolvimento sustentável - $\mathbf{3}$ Meio ambiente como um fator informativo da atividade econômica e instrumento de afirmação da ordem social - 3.1 Nova racionalidade produtiva e desenvolvimento social - 3.2 A legitimidade e a eficácia das normas ambientais e de desenvolvimento social - 3.3 O sistema constitucional brasileiro - 4 A política nacional de produção de biodiesel - 4.1 Regras para uma política pública energética - 4.2 Padrões para a inclusão social - 4.3 Incentivos fiscais específicos - 5 Análise aprofundada do sistema implementado - 5.1 Eficiência das regras de inclusão social - 5.2 Conseqüências ambientais - $\mathbf{5 . 3}$ Viabilidade econômica do programa - 6 Conclusões - Referências

\section{Introdução}

Biodiesel é a denominação ao combustível derivado de biomassa renovável para uso em motores a combustão interna com ignição por compressão ou, conforme regulamento, para geração de outro tipo de energia, que possa substituir parcial ou totalmente combustíveis de origem fóssil. ${ }^{1}$ Pode ser extraído de várias fontes vegetais, tais como soja, canola, palma, babaçu, etc., e representa uma fonte de combustível com menor impacto ambiental do que o apresentado pelo óleo diesel derivado do petróleo. Dentre as várias vantagens apresentadas,

\footnotetext{
* E-mail: <fernando@fernandobarros.adv.br>.

Art. 6०, XXV, Lei n 9.478/1997.
} 
podemos citar o processo de queima mais eficiente de carbono, o que acarreta uma sensível diminuição da emissão de hidrocarbonetos, monóxido de carbono, sulfatos, hidrocarbonetos aromáticos policíclicos e material particulado.

A busca pela substituição do atual modelo energético, baseado em combustíveis fósseis, tem causado um movimento de adaptação dos agentes econômicos. Novos setores econômicos e oportunidades de investimento surgiram com essa necessidade de substituição, assim como a pressão do próprio mercado consumidor para que isto aconteça. Este cenário conduz a uma releitura de como são realizadas as políticas públicas, pois o fluxo de recursos necessários à adaptação da produção pode ser estimulado e condicionado à prévia melhoria das condições de vida das classes mais pobres. No contexto social brasileiro, seria possível unir o incentivo a uma produção ambiental sustentável e melhorar a qualidade de vida dos seus cidadãos.

O Direito, como um organizador da vida social, possui uma função instrumental na realização dessas políticas. Como o conceito de desenvolvimento sustentável inclui a garantia de uma adequada qualidade de vida a todos, o ordenamento deve refletir uma estrutura dedicada à produção ecologicamente correta e buscar o desenvolvimento social. A partir da atual concepção jurídica do que seja desenvolvimento sustentável, será analisado o sistema normativo brasileiro de uso de biodiesel. Deste modo, será possível analisar como o Direito pode interferir no sistema produtivo para realizar o objetivo descrito acima, o que pode representar um padrão de ação para todos os países latino-americanos.

\section{Desenvolvimento social como integrante do conceito de desenvolvimento sustentável}

\subsection{Direito ao meio ambiente ecologicamente equilibrado}

O direito ao meio ambiente ecologicamente equilibrado não é apenas uma inovação normativa no texto constitucional, mas uma direção estrutural do Estado brasileiro. Esta tendência, verificada em alguns países da América Latina, ${ }^{2}$ representa um Estado dito pós-social, caracterizado por uma extensão da proteção estatal contra as novas contingências sociais que surgiram no

\footnotetext{
Além do art. 225 da Constituição Federal, podemos verificar exemplos na Constituição Argentina (art. 41), Chilena (art. 8), Uruguaia (art. 47) e, em especial, na Mexicana: Toda persona tiene derecho a un medio ambiente adecuado para su desarrollo y bienestar (art. $4^{\circ}$ ).
} 
século XX, tais como as relações de consumo, o meio ambiente, dentre outros exemplos. ${ }^{3}$ Somente a partir deste contexto podemos compreender a dimensão do direito ao meio ambiente ecologicamente equilibrado no ordenamento jurídico brasileiro. A partir desta dimensão estrutural do Estado e do conteúdo do art. 225 da Constituição Federal, podemos afirmar que representa um direito fundamental dos cidadãos, o que revela $o$ direcionamento das ações estatais para garantir a preservação ambiental, assim como a impossibilidade de supressão deste direito por emenda constitucional (art. 60, $\S 4^{\circ}, \mathrm{IV}$ ).

A partir disso, devemos considerar que o meio ambiente não representa um direito fundamental nos moldes originais (primeira dimensão), ou seja, uma simples ação negativa do Estado na esfera subjetiva dos indivíduos. A maioria dos exemplos práticos observados mostra que garantir o meio ambiente ecologicamente equilibrado representa o próprio exercício do poder do Estado, por meio de ações afirmativas para impedir a prática de atividades prejudiciais ao meio ambiente. Assim, esta dimensão do direito fundamental não consegue explicar satisfatoriamente este direito fundamental. Não representa, também, um direito fundamental de segunda dimensão, voltado à equiparação material dos cidadãos e à correção das distorções originadas no Estado liberal, ou seja, os chamados direitos sociais. $\mathrm{O}$ direito ao meio ambiente não é voltado somente às pessoas individualmente consideradas. Embora o exercício deste direito seja individual, a titularidade deste está acima das esferas jurídicas dos indivíduos, ou seja, está na coletividade. ${ }^{4}$ Representa, então, um direito fundamental de terceira dimensão, voltado a direitos de titularidade difusa e importância capital ao bom funcionamento da sociedade.

Assim, é possível afirmar que o meio ambiente é tratado como bem coletivo, pois é extensível a todos os cidadãos, não podendo ser tratado como algo divisível ou individualizável. Pode-se dizer, também, que é

\footnotetext{
A doutrina, geralmente, estabelece o surgimento do Estado pós-social como um desdobramento da incapacidade do Estado do Bem-Estar social em promover uma proteção efetiva dos indivíduos. Silva estabelece essa nova perspectiva de estrutura filosófica do Estado como associado a uma terceira geração de direitos humanos em novos domínios da vida em sociedade, como é o caso do ambiente e da qualidade de vida (...). Por fim, adiciona que Em causa está, uma vez mais, o retorno à idéia de proteção do indivíduo contra o poder, acentuando a idéia de defesa das pessoas contra novas ameaças provenientes tanto de entidades públicas como privadas, sem que isso signifique pôr em causa a necessidade de garantia dos direitos através da acção estadual (SILVA. Verde cor de direito: lições de direito do ambiente, p. 23).

4 Esse conceito é amplamente difundido na jurisprudência brasileira, o que reforça o exposto acima, conforme pode ser visto em: TRF 4a ${ }^{2} 4^{a}$ T, Ap. em Ação Civil Pública 1998.04.01.009684-2-SC, rel. Joel Ilan Paciornik, DJU, 16 abr. 2003.
} 
indisponível, pois é indispensável para o desenvolvimento do ser humano, não podendo ser renunciado. A fruição do direito ao meio ambiente equilibrado é individual, mas sua titularidade é difusa na sociedade. Por fim, o direito é exigível até mesmo contra o próprio Estado, o que é observado em duas perspectivas. Revela tanto o dever do Estado em promovê-lo por meio de ações positivas na sociedade, quanto a possibilidade de os próprios particulares interferirem na vida social e exigi-lo, seja por meio dos instrumentos judiciais disponibilizados pelo ordenamento, ${ }^{5}$ ou pela participação democrática nas decisões administrativas. ${ }^{6}$

Nesta parte do trabalho, podemos verificar que o direito do meio ambiente ecologicamente equilibrado é um direito fundamental de terceira dimensão, resultado de uma concepção pós-social de Estado. É um direito difuso, cujo exercício é individual e a titularidade é coletiva e que não pode ser renunciado ou alienado pelos cidadãos. Por fim, dependendo do sistema jurídico, pode ser exigido até contra o Estado por meio do direito de ação.

\subsection{Desenvolvimento social como consequência do desenvolvimento sustentável}

O direito ao meio ambiente não significa somente a proteção do ambiente natural contra a ocupação e uso humano do solo e águas, se considerarmos o desenvolvimento sustentável como o exercício das variadas atividades humanas, econômicas ou não, dentro das possibilidades físicas, químicas e biológicas dos recursos naturais disponíveis. Este conceito é mais amplo, pois influencia várias perspectivas de vida dos cidadãos, as quais serão traçadas resumidamente a seguir.

A busca pelo desenvolvimento sustentável determina a necessidade da existência de um meio ambiente equilibrado aos cidadãos. Além disto, as atividades humanas não poderão desequilibrar as relações naturais existentes, sob pena de esgotarmos os recursos naturais existentes e tornarmos a vida humana insuportável. Desse modo, a atividade econômica, por exemplo, somente pode se desenvolver em um contexto que possibilite a mitigação ou compensação dos impactos ambientais que realiza na

\footnotetext{
5 A legislação brasileira permite o exercício do direito de ação para garantia do direito ao meio ambiente (art. $1^{\circ}$, Lei nacional $\left.n^{\circ} 7.347 / 85\right)$. Um exemplo de norma constitucional que permita o direito de ação neste caso é encontrado no ordenamento argentino, conforme o art. 43 desta Constituição.

6 SILVA. Direito fundamental ao meio ambiente ecologicamente equilibrado. Revista de Direito Ambiental, p. 236
} 
natureza. Quanto à disposição de um meio ambiente equilibrado à população, deve ser observada a obrigatoriedade da manutenção de uma sadia qualidade de vida a todos. Somente a confluência sã de fatores ambientais sob os pontos de vista biológicos, físicos, químicos e psicológicos pode proporcionar uma vida digna aos cidadãos. ${ }^{7}$ A qualidade de vida das pessoas não significa, então, somente a ausência do estado de doença, mas também os incômodos que o desequilíbrio ambiental pode causar aos cidadãos. ${ }^{8}$

Desse modo, as condições de moradia e vida da população, por exemplo, devem preencher condições mínimas para uma vida saudável dos habitantes. ${ }^{9}$ Outro exemplo que pode ser citado é voltado às relações de trabalho. As condições de trabalho dos empregados não podem expôlos a situações adversas à manutenção da vida, tais como contato direto com substâncias nocivas, ambiente de trabalho estressante, etc. Por fim, a inserção das populações de baixa renda. Em suma, o desenvolvimento social da população está diretamente ligado à sustentabilidade da economia, se visualizarmos o direito ao meio ambiente sob esta perspectiva. A existência de um modelo econômico que não permita a degradação dos recursos naturais, por si só, proporciona a melhora da qualidade de vida dos indivíduos e proporciona desenvolvimento humano, quando proporciona uma melhor qualidade de vida às pessoas.

\section{Meio ambiente como um fator informativo da atividade eco- nômica e instrumento de afirmação da ordem social \\ 3.1 Nova racionalidade produtiva e desenvolvimento social}

A exploração da atividade econômica tem uma inegável relação com a apropriação e uso dos recursos naturais. Todas as indústrias e serviços dependem direta ou indiretamente da gestão destes recursos, o que requer uma grande atenção por parte do Estado e da sociedade civil para a dinâmica entre economia e preservação dos recursos naturais. Não se deve esquecer que um dos papéis da atividade econômica é a aquisição de lucro. Nesta perspectiva, considerando um contexto econômico em que não há regulamentação ambiental, a falta de sustentabilidade da atividade

\footnotetext{
MACHADO. Direito ambiental brasileiro, p. 121.

Deve ser levado em conta que não somente o ambiente nocivo à saúde proporciona o exercício do direito ao meio ambiente. A poluição sonora e visual das grandes cidades, por exemplo, representa um obstáculo à sadia qualidade de vida da população, pois a põe em um estado de desconforto diário que pode acarretar uma série de doenças futuras.

9 Podemos observar um exemplo disso na Constituição do Uruguai, que determina o condicionamento dos planos de águas e esgoto aos princípios ambientais (art. 47).
} 
econômica não representa um problema financeiro ou de produção. Pelo contrário, a correção da agressividade da atividade ao meio ambiente representa um custo para a empresa, que diminui a eficiência econômica e a capacidade de produzir riqueza.

De fato, a competitividade do mercado e a necessidade de gerar a maior quantidade de lucro fazem com que as empresas não tomem qualquer iniciativa ambiental, caso não sejam pressionadas a isto. Embora o comportamento do mercado consumidor possa pressionar os fabricantes à melhoria de seus sistemas de produção, um sistema regulatório ainda atinge resultados mais satisfatórios. Esta conclusão é mais bem explicada no estudo de Kagan, Thornton e Guinningham, que realizou um comparativo entre as administrações de empresas fornecedoras de água potável em diversos sistemas regulatórios. Mostrou fatos interessantes que poderiam ser utilizados para explicar o contexto contemporâneo. O estudo afirma a visão pragmática do empreendedor acerca das medidas ambientais cabíveis e os custos envolvidos. Não haverá nenhuma ação se não houver prévia determinação por normas regulamentares. Assim, os líderes institucionais do país possuem a função de desenvolver sistemas regulatórios e políticas públicas que estabeleçam parâmetros ambientais mínimos ao empreendedor e o estimulem à adoção de uma cultura sustentável de produzir. ${ }^{10}$

Nesse contexto, vários países adotaram posturas diferentes para o desenvolvimento das economias locais, concentrando-se na integração entre o desenvolvimento da atividade econômica e o equilíbrio dos recursos naturais, devido à crescente preocupação com o iminente colapso dos recursos naturais. ${ }^{11}$ Enquanto o ajuste do setor produtivo representa um custo monetário para a sua realização, a possibilidade de um colapso dos recursos naturais restantes torna economicamente viável a busca por formas alternativas de produzir. No entanto, estas ações não visam à subordinação da economia ao meio ambiente, nem alcançar o oposto. A solução

\footnotetext{
10 Yet it is becoming apparent that an increasing number of companies now perform, to a greater or lesser extent, "beyond compliance" with existing regulatory requirements. This suggests that the degree of variation in, and the motivations for, corporate behavior may be much broader than many researchers have imagined. This is of practical importance: some existing regulatory strategies, in focusing on compliance, have failed to facilitate, reward, or encourage beyond-compliance behavior, or even inadvertently discourage it, 2 while other regulatory reformers, in contrast, have argued that government-mandated self-regulation is the key to progress (KAGAN; THORNTON; GUINNINGHAM. Explaining Corporate Environmental Performance: How Does Regulation Matter?. Law \& Society Review, p. 53).

11 Vários estudos apontam para o provável colapso dos recursos naturais globais. A WWF demonstrou recentemente que a sociedade humana consome $30 \%$ a mais do que a capacidade regenerativa dos recursos naturais mundiais. Isto pode ser verificado no estudo intitulado Living Planet 2008 Report. Disponível em: $<$ http://www.wwf.org.uk/news_feed.cfm?uNewsID=2294>.
} 
político-jurídica deve atingir o máximo desenvolvimento econômico dos agentes econômicos e determinar a cultura da incorporação das determinações ambientais como parte dos custos de investimento. ${ }^{12}$ No entanto, isso deve ser realizado dentro do grau de suportabilidade dos recursos naturais, sob a ameaça de intervenção do Estado por meio de uma estrutura de regulação ou exercício do poder de polícia. ${ }^{13}$ Este contexto econômico e jurídico gera um fluxo de investimentos direcionados à adaptação do setor produtivo às novas diretrizes ambientais. A iniciativa privada e o Estado não só absorvem os custos de adaptação do setor produtivo, mas buscam formas de geração de renda por meio de mecanismos que possibilitem uma menor produção ambientalmente degradante. ${ }^{14}$

Isso está ligado ao desenvolvimento social da população de duas maneiras diferentes. A primeira, já discutida anteriormente no item 2.2, quando se afirma que a garantia do direito ao meio ambiente ecologicamente equilibrado proporciona também o desenvolvimento social da população, se considerarmos que o meio ambiente ecologicamente equilibrado envolve não só físicos, químicos e biológicos, mas também aspectos sociais e psicológicos do comportamento. A segunda maneira se refere à possibilidade de utilização deste fluxo de recursos para estimular o desenvolvimento social e reduzir as desigualdades regionais. Visto que o Estado possuiria o compromisso de promover o desenvolvimento humano da população e um meio ambiente adequado, é perfeitamente possível a vinculação de recursos de financiamento destinados à modificação do setor produtivo, por exemplo, à realização de objetivos sociais.

Tal como acima demonstrado, o desenvolvimento social possui uma estreita relação com o desenvolvimento sustentável da economia. Como atividade econômica depende da apropriação dos recursos naturais para a produção de bens econômicos, bem como influencia ambiente ao redor com os processos industriais utilizados, é vital para a sociedade do equilíbrio entre a produção mais eficiente possível e a suportabilidade possível

\footnotetext{
12 NAPOLITANO. Relações entre o direito ambiental e o direito econômico. Revista de Direitos Difusos - Direito Econômico e Meio Ambiente, p. 3367.

13 A Constituição Federal estabelece o respeito ao meio ambiente como orientador da atividade econômica (art. 170, VI). Isso também é visto na Constituição mexicana, na qual há uma clara referência à necessidade de busca do desenvolvimento sustentável nacional (art. 25). De forma mais genérica, a Constituição chilena estabelece a possibilidade de restrição das atividades econômicas pelo Estado em prol do meio ambiente $\left(\operatorname{art.} 8^{\circ}\right)$.

14 Grandes investimentos têm sido realizados em tecnologias "limpas" pelas grandes companhias internacionais, como a General Eletric na reportagem da BBC chamada GE doubles spend on green agenda. Disponível em: $<$ http://news.bbc.co.uk/2/hi/business/4531325.stm >.
} 
dos recursos naturais disponíveis. Visto que há a necessidade de adaptação da economia a novos processos de produção e o dever estatal de incentivo à produção ambientalmente correta e justiça social, é perfeitamente possível vincular incentivos sociais aos incentivos econômicos destinados ao mercado.

\subsection{A legitimidade e a eficácia das normas ambientais e de desen- volvimento social}

A partir dos temas discutidos anteriormente, a promoção de uma economia ecologicamente sustentável é um ponto comum entre os sistemas constitucionais dos Estados latino-americanos. Não há dúvidas sobre a legitimidade política destas normas, mas existe um problema claro de eficácia. Na maioria destes Estados, o aparelho governamental é insuficiente para alcançar os efeitos desejados de controle do meio ambiente. A simples determinação legal direcionada a uma produção sustentável não representa em si um estímulo para a modificação de uma racionalidade de produção e consumo da economia. Logo, mesmo com todo o aparelho coercitivo e financeiro do Estado, as mudanças necessárias dos agentes econômicos são realizadas aquém do esperado pela sociedade.

Isso não pode ser determinado como inércia dos agentes econômicos. Conforme abordado anteriormente, o custo da melhoria ambiental da produção representa um obstáculo insuportável em muitos casos. O custo elevado e a concorrência entre agentes econômicos acabam com qualquer iniciativa para uma produção ambientalmente sustentável. Assim, o Estado, ao lado de um conjunto de normas que garantam a conformidade ao meio ambiente, deve promover um sistema de incentivos que não só permitam a entrada dos agentes econômicos no processo de adaptação produtiva, mas que favoreçam o desenvolvimento da população neste processo. ${ }^{15}$ Trata-se, então, de uma ação afirmativa para orientar os agentes econômicos a um desenvolvimento econômico ambientalmente sustentável. Dois problemas podem ser resolvidos desta forma. Haveria a possível eliminação da inércia dos agentes econômicos, assim como se estimularia a existência de empreendedores voltados à promoção de atividades econômicas de adaptação do sistema produtivo. Esse contexto permitiria um real

15 Muitos países desenvolvidos já direcionam ações neste sentido. A recente Farm Bill (2008) permitiu o gasto de aproximadamente US\$1,1 bilhões em combustíveis alternativos e pesquisa nos próximos três anos, conforme o serviço de pesquisa legislativa do congresso Americano, em <http://opencrs.com/document/ RL34130>. Isso também pode ser visto no Reino Unido, conforme reportagem da BBC chamada Sci/TeC Green energy boost. Disponível em: <http://news.bbc.co.uk/2/hi/science/nature/307463.stm>. 
auxílio ao Estado para a implementação de novos parâmetros industriais de sustentabilidade.

Para que essa situação seja atingida, os estímulos utilizados devem representar um custo-benefício mínimo para alcançar o objetivo de promoção de um desenvolvimento econômico e social sustentável. Significa o estímulo a um contexto econômico mais favorável ao empreendedor, para que seja possível a preferência às medidas solicitadas pelo Estado em detrimento de uma produção ecologicamente incorreta. Isto leva à afirmação de que apenas um quadro regulamentar que equivalha a importância do meio ambiente à atividade econômica é capaz de determinar uma situação econômica favorável e a segurança jurídica necessária para o moderno conceito de desenvolvimento sustentável.

Como resultado, um sistema de regulação que vai além da simples determinação de princípios e regras e direciona materialmente o sistema econômico a uma nova racionalidade da produção e do desenvolvimento social é a melhor opção. No entanto, estes incentivos devem ser objetivos e suficientes para viabilizar economicamente os objetivos ambientais e sociais pretendidos pelo Estado.

\subsection{O sistema constitucional brasileiro}

Para que seja possível a análise do exemplo trazido pela Política Nacional de Uso de Biocombustíveis (PNPB), deve ser analisada a situação normativa constitucional brasileira acerca do tema. A Constituição brasileira apresenta uma relação de fundamentos da República, os quais são demonstrados em seu art. $1^{\circ}$. Dentre os objetivos listados, está a dignidade da pessoa humana, conforme consta no inciso III. Além disso, estabelece como objetivos da República o desenvolvimento nacional (art. $3^{\circ}$, II) e o bem de todos (art. $3^{\circ}$, IV). Estas normas possuem um papel importante no conjunto normativo da Constituição, que é o de informar o direcionamento político-filosófico da interpretação das demais normas e princípios constitucionais.

A doutrina analisa esta estrutura de fundamentos constitucionais conforme a conclusão exposta acima. Silva ${ }^{16}$ aponta que os fundamentos expressos na Constituição Federal representam uma forma de garantia geral dos direitos fundamentais, pois estes asseguram a existência e efetividade

16 SILVA. Curso de direito constitucional positivo, p. 188. 
destes. Em uma análise similar, Derani apresenta os fundamentos da Constituição brasileira sob a denominação em princípios "essência". Afirma que, ao lado dos princípios fundamentais, existem diretrizes que determinam a finalidade máxima da República e que tornam possível uma unidade interpretativa da Constituição, as quais estão determinadas no art. $1^{\circ} .{ }^{17}$

É nesse contexto normativo que devemos ponderar os princípios do meio ambiente ecologicamente equilibrado, os da ordem econômica e os da ordem social. O art. 170, caput, da Constituição brasileira afirma o fundamento constitucional da dignidade da pessoa humana como finalidade da ordem econômica. O papel hermenêutico deste dispositivo permite afirmar que a atividade econômica não visa somente ao desenvolvimento e à expansão do mercado, mas demonstra a necessidade de prover aos cidadãos a capacidade de produzir riquezas e usufruir a melhor qualidade de vida possível. Tudo isso sob a diretriz da menor agressão viável aos recursos naturais.

Além disso, a realização do meio ambiente ecologicamente equilibrado permite a adequada qualidade de vida necessária à realização da ordem social, uma vez que o bem-estar é uma das bases desta, conforme o art. 193 da Constituição Federal. Assim, o desenvolvimento econômico nacional deverá promover o engrandecimento das riquezas monetárias da nação, assim como preservar a integridade dos recursos naturais e ser um instrumento de inclusão e desenvolvimento de todos os estratos da sociedade.

\section{A política nacional de produção de biodiesel}

O conceito de desenvolvimento sustentável exposto acima é claramente utilizado na legislação brasileira de biodiesel. É um sistema normativo que estabelece diretrizes para políticas públicas, medidas de estímulo à inclusão social (especialmente em relação à agricultura de baixa renda familiar) e um sistema de incentivos fiscais para encorajar o setor econômico privado para produzir este combustível.

\subsection{Regras para uma política pública energética}

A Lei ${ }^{\circ} 11.097 / 2005$ representa o principal instrumento normativo do biodiesel no Brasil. Em primeiro lugar, deve ser destacada a mudança do art. $1^{\circ}$ da Lei $n^{\circ} 9.478 / 1997$, que determinou o desenvolvimento dos biocombustíveis como uma das diretrizes da política energética nacional.

17 DERANI. Direito ambiental econômico, p. 249. 
Outro fator importante presente na lei é o planejamento da substituição do consumo de diesel fóssil por biodiesel. Até 2013, o volume de biodiesel na composição total do diesel comum vendido aos consumidores no território nacional deverá ser de pelo menos $5 \%$ (art. $2^{\circ}, \S 1^{\circ}$ ). Para tanto, é determinado o seguinte procedimento de transição: no período compreendido entre os anos 2008 e 2013, o volume obrigatório é de $2 \%$ de biodiesel, modificáveis por Resolução do Conselho Nacional de Política Energética - CNPE (art. $2^{\circ}, \S 2^{\circ}$, Lei $\left.n^{\circ} 11.097 / 2005\right)$. Essa última informação é importante, pois houve a recente edição da Resolução ${ }^{\circ}$ 02/2008 do CNPE, que aumentou o volume mínimo para $3 \%$ do volume total de composição a partir de julho/2008.

\subsection{Padrões para a inclusão social}

Medidas para inclusão de produtores familiares no mercado produtivo estão entre os incentivos econômicos destinados à produção de biodiesel, o que reforça o conceito mostrado no item $\mathrm{n}^{\circ} 2$. Em caráter geográfico, observa-se a preocupação em desenvolver as regiões mais pobres do país por meio de incentivos específicos à produção. A Lei n ${ }^{\circ} 11.097 / 2005$, por exemplo, afirma que a matéria-prima para fabricação do biodiesel deverá, preferencialmente, ser fornecida pela agricultura familiar ou atividade extrativista (art. $2^{\circ}, \S 4^{\circ}$ ). Outro exemplo pode ser visto no mecanismo visto no art. $5^{\circ}$ da Lei ${ }^{\circ} 11.116 / 2005$. Este determina que o Poder Público possa conceder diferentes alíquotas de incentivos econômicos aos agentes econômicos, baseadas no tipo de matéria-prima utilizada na produção de biodiesel, na origem geográfica da produção e na capacidade econômica do produtor de matéria-prima. É possível, então, que haja incentivos especiais aos pequenos agricultores familiares, assim como o estímulo à produção de biodiesel nas regiões menos desenvolvidas do Brasil por meio da redução dos custos de produção.

Seguindo esta racionalidade, foi criado o Selo Combustível Social, que consiste no reconhecimento oficial de que o produtor de biodiesel respeita as regras de inclusão social determinadas pela Lei ${ }^{\circ}$ 11.097/2005 e Resoluções n ${ }^{\circ}$ 01/2005 e 02/2005 do Ministério do Desenvolvimento Agrário. Entre os requisitos básicos para o recebimento do selo, podem ser citados: a) o percentual mínimo de matéria-prima comprada de agricultores familiares, cujo montante será definido de acordo com a região do país (art. $2^{\circ}$, Resolução ${ }^{\circ}$ 01/2005-MDA); b) a obrigatoriedade de prestação de assistência técnica aos agricultores contratados para apoio à produção 
(art. $7^{\circ}$, Resolução $\mathrm{n}^{\circ}$ 01/2005-MDA). Possuir o selo possibilita o usufruto de condições especiais de financiamento pelo produtor de biodiesel. A Resolução ${ }^{\circ}$ 1.135/2004 do Banco Nacional de Desenvolvimento (BNDES) concede financiamento de até $90 \%$ do custo total dos projetos direcionados para a produção de biodiesel. Se o produtor não possui o selo, esse percentual cai para $80 \%$ do custo total do projeto de produção.

\subsection{Incentivos fiscais específicos}

A lei federal prevê incentivos fiscais tanto para o produtor de matériasprimas como para o produtor de biodiesel. Este combustível é isento do Imposto sobre Produtos Industrializados (IPI), conforme o último quadro deste tributo publicado junto ao Decreto $\mathrm{n}^{\circ}$ 6.006/2006. Além disso, o sistema fiscal nacional permite a redução (e até mesmo a isenção) de PIS/ COFINS, o que é observado no art. $4^{\circ}$ do Decreto $n^{\circ} 5.297 / 2004$. Neste último caso, convém observar que o formato de incentivo varia de acordo com as matérias-primas envolvidas e região produtora, o que demonstra o mecanismo visto no art. $5^{\circ}$ da Lei $n^{\circ} 11.116 / 2005$.

A partir dos exemplos acima, são verificados os dois principais objetivos destas regras fiscais. A primeira se refere à clara intenção de utilizar o desenvolvimento do biodiesel como instrumento para a redução das desigualdades regionais, o que se reflete nos benefícios fiscais concedidos às regiões produtoras no Norte e Nordeste do Brasil. A segunda é vinculada ao fomento da produção de biodiesel. A diminuição da carga fiscal diminui o custo final do combustível, o que aumenta a viabilidade econômica da produção e permite a consolidação do mercado produtor e consumidor.

\section{Análise aprofundada do sistema implementado}

Como já foi observado nos itens anteriores, a Política Nacional de Produção e Uso de Biodiesel contém um sistema normativo que envolve orientações para a política energética brasileira, incentivos econômicos específicos e medidas para o desenvolvimento social dos pequenos produtores. Representa um conjunto de medidas direcionadas a uma produção menos poluente e a um melhor desenvolvimento social do país, especialmente nas regiões mais pobres. Esta diversidade de normas e ações mostra os pontos positivos do programa. Existe uma clara tentativa de obtenção do desenvolvimento social em porções específicas da população, bem como a redução da desigualdade econômica entre as regiões geográficas do Brasil. Além disso, a substituição de parte da matriz energética brasileira busca 
atenuar os efeitos do uso de combustíveis fósseis, que representam parte importante da matriz energética brasileira.

Apesar do bom prognóstico demonstrado no sistema normativo, houve alguns problemas encontrados na execução do programa que merecem atenção. A análise destes fatos mostra o caminho para uma melhor execução das políticas públicas nacionais e responde a algumas questões sobre a relação entre economia, proteção ambiental e redução da pobreza. Por uma questão didática, a análise será realizada em três perspectivas: a) social; b) ambiental; c) econômica.

\subsection{Eficiência das regras de inclusão social}

A partir do sistema jurídico delimitado acima, existe um compromisso governamental para estimular o desenvolvimento econômico e ecológico nas regiões mais pobres do Brasil, notadamente as regiões norte e nordeste. Como visto nos itens 4.2 e 4.3, existe um sistema de benefícios econômicos e fiscais específicos ao agricultor familiar e fornecedor de matéria-prima para produção de biodiesel. Nestas regiões, os benefícios são superiores aos observados no resto do país, o que revela o claro objetivo de incentivo ao crescimento econômico e social e integração regional.

Assim, comparar os resultados obtidos pelas regiões mais pobres com as regiões mais desenvolvidas do Brasil demonstra um método de avaliação da eficiência do programa. Se utilizarmos os números do mapa geográfico de produção de biodiesel, podemos observar alguns fatos interessantes. Isto pode ser observado no gráfico de aquisição de biodiesel por região, verificado na $11^{a}$ hasta pública para aquisição de biodiesel:

\section{Volume arrematado por região}

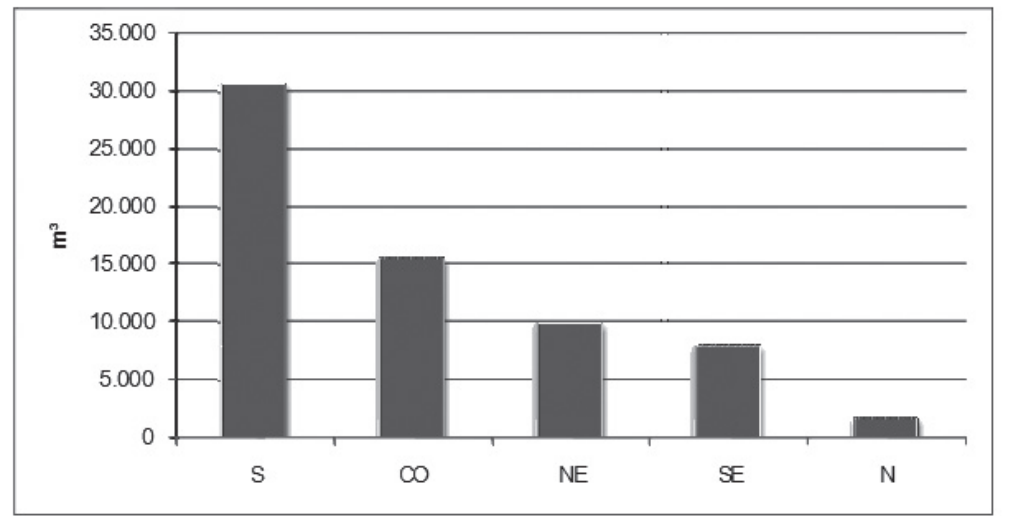

Fonte: ANP. <http://www.anp.gov.br/doc/biodiesel/leiloes/resultado_11_leilao.pps>. 
Estes números revelam um desempenho quantitativo fraco das regiões brasileiras mais pobres (Norte - N; Nordeste - NE), quando comparadas às demais regiões. Se compararmos o gráfico acima aos dados de produção de biodiesel obtidos nos últimos três anos, ${ }^{18}$ observa-se um forte crescimento na produção de biodiesel das regiões mais ricas, assim como a quase estagnação da produção nas regiões mais pobres. Apesar do curto período de existência do programa, o principal fato é que as regiões mais estimuladas a produzir biodiesel e matérias-primas não respondem de forma eficaz às medidas previstas no ordenamento jurídico brasileiro.

A conclusão preliminar é que os estímulos distribuídos à cadeia produtiva não são suficientes para viabilizar a produção. Os custos de produção estão sendo afetados por fatores distintos e mais intensos do que a carga tributária renunciada e o crédito facilitado pelo Estado. Assim, é possível verificar que o desenvolvimento econômico e social dessas regiões é mais complexo do que simplesmente garantir incentivos econômicos e tributários aos eventuais empreendedores interessados.

É preciso considerar, então, quais são esses fatores. Se analisarmos toda a produção científica geográfica até então, será observado que ambas as regiões possuem grande quantidade de recursos naturais e a falta de um modelo de desenvolvimento adequado. Esta carência é originada em vários fatores, tais como o modo de colonização na região, estruturas de poder deficientes ou descomprometidas com a realização das garantias fundamentais, etc. A continuidade destas falhas de organização social acarretou uma séria carência estrutural na região, o que é observado nos sistemas públicos essenciais como transporte, saúde, educação, etc. A conseqüência é clara: a falta de estrutura repercute diretamente nos custos de produção do combustível.

Além do fator estrutural, há o fator social. Para a elaboração de um cenário, deve-se conjugar a pobreza da região, falta de presença do Estado na região, a falta de compromisso do poder local em promover o desenvolvimento da população e as vastas riquezas naturais de ambas as regiões. Os resultados são a forte dependência econômica da população rural aos detentores do poder, assim como uma resistência político/social na modificação desta estrutura social. Isto se dá a ponto de a população possuir um sentimento quase hierárquico com estes grupos sociais dominantes, assim

18 BRASIL. ANP. Relatório de produção de biodiesel puro (B100). Disponível em: <http://www.anp.gov.br/doc/ dados_estatisticos/Producao_de_biodiesel_m3.xls $>$. 
como a desconfiança perante investimentos externos e falta de qualquer ligação institucional com o Estado. Este contexto é muito bem demonstrado por Glasmeier e Farrigan, quando descrevem um contexto social muito semelhante (Appalachia). ${ }^{19}$

Desse modo, a concepção do plano de uso de biodiesel deve ser mais ampla, pois essas barreiras geográficas promovem insegurança nos investidores, dúvidas quanto ao retorno dos recursos despendidos e séria desconfiança quanto ao alcance dos benefícios econômicos ao agricultor familiar. Como já afirmado acima, não só o estímulo econômico é suficiente para promoção do desenvolvimento sustentável dessas regiões, mas uma modificação da relação entre o cidadão e o Poder público. Tal como o exemplo estrangeiro acima, parece evidente que o conjunto básico de relações sociais de confiança dos cidadãos nas instituições públicas ainda não está desenvolvido. ${ }^{20}$ A solução visível, neste contexto, é a implantação da presença do Estado nestas áreas por meio da eliminação das deficiências estruturais existentes, assim como o desenvolvimento educacional da população. Estas medidas eliminariam a cadeia de poder disseminada na população local e criariam as condições ideais para o recebimento de investimentos.

\subsection{Conseqüências ambientais}

Preliminarmente, devemos realizar alguns esclarecimentos acerca das matérias-primas do biodiesel. O combustível pode ser extraído do óleo de uma série de espécies vegetais, conforme apontado na tabela produzida pelo estudo interministerial realizado acerca do tema: ${ }^{21}$

\footnotetext{
19 The historical legacy of resource extraction in the region, coupled with the effects of outside ownership, produced an economy heavily dependent on a few sectors and a citizenry deeply suspicious of outside interests and fearful of the local power structure (GLASMEIER; FARRIGAN. Poverty, Sustainability, and the Culture of Despair: Can Sustainable Development Strategies Support Poverty Alleviation in America's Most Environmentally Challenged Communities?. The Annals of the American Academy of Political and Social Science. Rethinking Sustainable Development. p. 141).

20 GLASMEIER; FARRIGAN, op. cit., p. 147.

${ }^{21}$ BRASIL. Grupo de trabalho interministerial: biodiesel relatório final. Disponível em: $<$ http:// www. biodiesel.gov.br/docs/relatoriofinal.pdf >.
} 
Eficiência em óleo dos recursos vegetais

\begin{tabular}{|c|c|}
\hline Espécie & Eficiência em óleo \\
\hline Algodão & 30 a $40 \%$ \\
\hline Amendoim & 40 a $50 \%$ \\
\hline Rice & 15 a $23 \%$ \\
\hline Babaçu & 58 a $67 \%$ \\
\hline Coco & 50 a $65 \%$ \\
\hline Colza & 39 a $45 \%$ \\
\hline Gergelim & 48 a $55 \%$ \\
\hline Girassol & 45 a $55 \%$ \\
\hline Linhaça & 35 a $45 \%$ \\
\hline Mamona & 45 a $55 \%$ \\
\hline Milho & 30 a $36 \%$ \\
\hline Dendê & 35 a $45 \%$ \\
\hline Palma & 55 a $65 \%$ \\
\hline Soja & 18 a $21 \%$ \\
\hline
\end{tabular}

Fonte: Abiove.

Algumas espécies vegetais, como a mamona e o girassol, rendem mais óleo e são mais eficientes do que a soja para produzir biodiesel. No entanto, esta é a maior lavoura comercial dentre as espécies acima e possui toda uma cultura científica acerca de eventuais pragas ou problemas de produção. A superioridade na área de plantio e crescimento das áreas de produção é comprovada no comparativo realizado pelo IBGE, ${ }^{22}$ conforme quadro a seguir:

\begin{tabular}{|l|r|r|r|r|r|r|r|}
\hline \multirow{2}{*}{ Lavoura } & \multicolumn{7}{|c|}{ Área (Hectare) } \\
\cline { 2 - 9 } & \multicolumn{1}{|c|}{$\mathbf{2 0 0 1}$} & \multicolumn{1}{|c|}{$\mathbf{2 0 0 2}$} & \multicolumn{1}{c|}{$\mathbf{2 0 0 3}$} & \multicolumn{1}{c|}{$\mathbf{2 0 0 4}$} & \multicolumn{1}{c|}{$\mathbf{2 0 0 5}$} & \multicolumn{1}{c|}{$\mathbf{2 0 0 6}$} & \multicolumn{1}{c|}{$\mathbf{2 0 0 7}$} \\
\hline Algodão & 893.150 & 763.992 & 719.074 & 1.159 .677 & 1.265 .618 & 910.382 & 1.125 .604 \\
\hline Amendoim & 105.125 & 97.125 & 89.211 & 105.434 & 136.429 & 111.623 & 106.174 \\
\hline Girassol & - & - & - & - & 48.668 & 67.829 & 73.233 \\
\hline Mamona & 176.534 & 132.051 & 134.485 & 176.090 & 242.057 & 160.332 & 167.062 \\
\hline Soja & 13.988 .351 & 16.376 .035 & 18.527 .544 & 21.601 .340 & 23.426 .756 & 22.082 .666 & 20.620 .720 \\
\hline
\end{tabular}

Fonte: IBGE.

Outro dado importante é o crescimento da área de soja verificado nesta década $(47 \%)$, o que é o elemento-chave para análise. Como será

22 BRASIL. IBGE. Sistema IBGE de recuperação automática - SIDRA. Disponível em: <http://www.sidra. ibge.gov.br>. 
tratado no próximo item, deve ser levado em conta que o contexto mundial reclama uma maior oferta de alimentos, assim como há a demanda por combustíveis alternativos. Na perspectiva ambiental, representa a necessidade imediata de um aumento das áreas de cultivo tanto de alimentos quanto de matérias-primas para fabricação de biodiesel, o que se reflete diretamente na área cultivada de soja. Se estes dados forem analisados em conjunto com a produção de carne bovina, será visto que a produção bovina está sofrendo um processo de migração decorrente do aumento da área de soja. Esta afirmativa pode ser confirmada pelas tabelas a seguir. ${ }^{23}$ Enquanto há um grande aumento do rebanho bovino na região amazônica (principalmente na região Norte do país), as demais regiões do país não possuem o mesmo ritmo de crescimento. Como já foi observado acima que as lavouras de soja representam a maior parte do aumento da fronteira agrícola brasileira, é possível afirmar que a soja é um fator determinante para que o rebanho bovino esteja sendo deslocado para a região Norte do país. ${ }^{24}$

\begin{tabular}{|l|r|r|r|r|r|r|r|}
\hline \multicolumn{7}{|c|}{ Soja } \\
\hline \multirow{2}{*}{ Brasil/Região } & \multicolumn{1}{|c|}{ Ano } \\
\cline { 2 - 9 } & \multicolumn{1}{|c|}{$\mathbf{2 0 0 1}$} & \multicolumn{1}{|c|}{$\mathbf{2 0 0 2}$} & \multicolumn{1}{c|}{$\mathbf{2 0 0 3}$} & \multicolumn{1}{c|}{$\mathbf{2 0 0 4}$} & \multicolumn{1}{c|}{$\mathbf{2 0 0 5}$} & \multicolumn{1}{c|}{$\mathbf{2 0 0 6}$} & \multicolumn{1}{c|}{$\mathbf{2 0 0 7}$} \\
\hline Brasil & 13.988 .351 & 16.376 .035 & 18.527 .544 & 21.601 .340 & 23.426 .756 & 22.082 .666 & 20.620 .720 \\
\hline Norte & 106.136 & 140.656 & 212.264 & 359.434 & 514.296 & 517.943 & 455.075 \\
\hline Nordeste & 966.165 & 1.125 .225 & 1.242 .515 & 1.321 .505 & 1.441 .161 & 1.488 .313 & 1.455 .734 \\
\hline Sudeste & 1.162 .418 & 1.294 .586 & 1.527 .857 & 1.876 .303 & 1.900 .077 & 1.665 .966 & 1.411 .032 \\
\hline Sul & 5.993 .431 & 6.860 .846 & 7.498 .175 & 8.309 .827 & 8.688 .656 & 8.131 .849 & 8.283 .922 \\
\hline Centro-Oeste & 5.760 .201 & 6.954 .722 & 8.046 .733 & 9.734 .271 & 10.882 .566 & 10.278 .595 & 9.014 .957 \\
\hline
\end{tabular}

Fonte: IBGE.

\begin{tabular}{|l|c|c|c|c|r|r|}
\hline \multicolumn{7}{|c|}{ Número de unidades } \\
\hline \multirow{2}{*}{ Brasil/Região } & \multicolumn{7}{c|}{ Ano } \\
\cline { 2 - 8 } & $\mathbf{2 0 0 1}$ & $\mathbf{2 0 0 2}$ & $\mathbf{2 0 0 3}$ & $\mathbf{2 0 0 4}$ & $\mathbf{2 0 0 5}$ & \multicolumn{2}{c|}{$\mathbf{2 0 0 6}$} \\
\hline Brasil & 176.388 .726 & 185.348 .838 & 195.551 .576 & 204.512 .737 & 207.156 .696 & 205.886 .244 \\
\hline Norte & 27.284 .210 & 30.428 .813 & 33.929 .590 & 39.787 .138 & 41.489 .002 & 41.060 .384 \\
\hline Nordeste & 23.414 .017 & 23.892 .180 & 24.992 .158 & 25.966 .460 & 26.969 .286 & 27.881 .219 \\
\hline Sudeste & 37.118 .765 & 37.923 .575 & 38.711 .076 & 39.379 .011 & 38.943 .898 & 39.208 .512 \\
\hline Sul & 26.784 .435 & 27.537 .047 & 28.030 .117 & 28.211 .275 & 27.770 .006 & 27.200 .207 \\
\hline Centro-Oeste & 61.787 .299 & 65.567 .223 & 69.888 .635 & 71.168 .853 & 71.984 .504 & 70.535 .922 \\
\hline
\end{tabular}

Fonte: IBGE.

23 IBGE, op. cit.

24 Essa conclusão também é partilhada pelo grupamento designado pelo Governo Federal (Ministério da Integração Regional) para o desenvolvimento do Plano Amazônia Sustentável, cujas constatações estão dispostas em (BRASIL. MIR. Plano Amazônia sustentável. Disponível em: <http://www.integracao.gov.br/ $\mathrm{pdf} /$ desenvolvimentoregional/pas.zip $>$ ). 
Essa questão é um exemplo prático de necessidade de aplicação do princípio da precaução. Existe um intenso movimento dos rebanhos bovinos em direção à Amazônia, provocado pela necessidade de expansão das áreas agricultáveis brasileiras (principalmente para a soja). Como a soja é a matéria-prima de maior utilização para fabricação de biodiesel, a demanda provocada poderá produzir um cenário perigoso na floresta amazônica, se considerarmos que a ocupação de gado acarreta a destruição da mata nativa. Qualquer política de desenvolvimento sustentável deve considerar o impacto ambiental direto e indireto da demanda brasileira por alimentos e combustíveis alternativos.

O problema acima possui duas perspectivas de análise. A primeira está relacionada ao desafio de organizar esses movimentos econômicos em um programa racional de zoneamento ambiental das áreas envolvidas. Uma série de estudos combinados pode determinar locais adequados à ocupação bovina, mesmo que localizados dentro da região amazônica. No entanto, somente uma estrutura adequada de fiscalização e controle que envolva tanto os órgãos do SISNAMA como o Poder Executivo e Tribunais de Contas pode conter os agentes econômicos e realizar os objetivos do zoneamento. Outra perspectiva de análise é a busca de formas mais eficientes de fabricação de biodiesel. Neste caso, somente grandes investimentos em pesquisa e desenvolvimento podem aliviar a pressão por novas áreas agricultáveis. ${ }^{25}$

\subsection{Viabilidade econômica do programa}

Embora este trabalho não seja voltado à análise econômica do programa brasileiro de uso e produção de biodiesel, possui o objetivo de verificar eventuais cenários regulatórios para o setor. Dessa forma, os cenários demonstrados a seguir visam a ilustrar as possíveis formas de ação estatal para manutenção do programa. Assim, a partir do exposto acima, os problemas que merecem uma observação mais acurada estão centrados na dependência do programa à soja e as flutuações do preço do petróleo.

Visto que a soja era a única fonte de óleo para biodiesel disponível em larga escala, a produção de biodiesel no Brasil se tornou sensível às flutuações de disponibilidade e preço deste insumo. Se observarmos os

\footnotetext{
${ }^{25}$ Um exemplo disso seria o aproveitamento do bagaço de cana para a fabricação do combustível (PROJETO busca combustível a partir do bagaço de cana. Gazeta Mercantil. Disponível em: < http:// indexet.gazetamercantil.com.br/arquivo/2005/11/28/314/Projeto-busca-combustivel-a-partir-do-bagaco-decana.html>).
} 
preços praticados nos últimos anos, observamos alguns fatos importantes. No Brasil, o preço da soja sofreu um aumento de $222 \%$ (duzentos e vinte e dois por cento) entre as datas do primeiro (novembro/2005) e último leilão (agosto/2008), ofertados pela Agência Nacional do Petróleo (ANP). ${ }^{26}$ Por outro lado, os preços pagos nos leilões não acompanharam o mesmo ritmo de crescimento no período, pois apresentaram alta de somente $36 \%$ (trinta e seis por cento).$^{27} \mathrm{~A}$ conseqüência imediata disto foi o gradual aumento dos custos de produção e diminuição das margens de operação das empresas produtoras, o que se revelou em sérios obstáculos à manutenção destas. ${ }^{28}$

Mesmo o recuo de $31 \%$ dos preços da soja entre agosto de 2008 e janeiro de 2009 não é suficiente para criar um contexto favorável ao desenvolvimento do setor de biodiesel. Ao passo que houve essa redução nos custos de produção, o preço do barril de petróleo representa hoje $32 \%$ do preço verificado em agosto de 2008 (US\$36,41).${ }^{29}$ À primeira vista, é observável uma queda mais drástica dos preços do petróleo e uma redução no total do montante financeiro necessário para a importação de diesel fóssil do país, o que causa uma diminuição natural do custo-benefício do biodiesel para a população.

É nesse contexto que as políticas públicas voltadas ao biodiesel devem ser o resultado da ponderação entre a manutenção do programa e os custos suportados pelo Estado. O custo dos benefícios concedidos aos empresários deve observar o montante que seria desempenhado pelo país com a substituição do diesel fóssil por biodiesel. Neste caso particular, se os custos econômicos ultrapassarem o montante que seria gasto com a importação de diesel fóssil, a intensidade deste custo adicional deve somar o mesmo valor em benefícios ambientais à população. Em suma, o público deverá ter os benefícios ambientais de um combustível verde a um custo que aprove e possa suportar, sob pena de haver o desrespeito aos princípios básicos da ordem econômica (art. 170 da Constituição Federal). ${ }^{30}$

${ }^{26}$ ABIOVE. Complexo soja: evolução das cotações médias. Disponível em: <http://www.abiove.com.br/ cotacoes br.html>.

27 Histórico das cotações oferecidas nos leilões disponibilizados no endereço eletrônico da Agência Nacional de Petróleo - ANP (BRASIL. ANP. Quinto leilão de biodiesel da ANP será dia 13 de fevereiro. Disponível em: $<$ http://www.anp.gov.br/conheca/noticias_int.asp?intCodNoticia=208/>).

28 Podemos citar os seguidos prejuízos das máiores empresas do setor produtivo como um indício do contexto econômico do biodiesel brasileiro (BRASIL. Ecodiesel tem terceiro prejuízo trimestral seguido. Gazeta Mercantil. Caderno C, p. 12. Disponível em: <http://indexet.gazetamercantil.com.br/arquivo/2008/08/18/71/BrasilEcodiesel-tem-terceiro-prejuizo-trimestral-seguido.html >).

${ }^{29}$ REUTERS. Petroleum daily cotation. Disponível em: <http://www.reuters.com>.

30 Breyer conceitua esta situação como um spillover, ou seja, como o custo social representado pelo desempenho de uma atividade econômica. Cita, como exemplo, a influência que uma ferrovia pode representar na 
O cenário disposto acima não se traduz na necessidade de abandono do programa. Significa a necessidade de comparação e discussão acerca de todos os benefícios (ambientais, sociais e econômicos) obtidos pela adoção do programa e os investimentos necessários à manutenção destes. A redução da dependência brasileira à soja, a pesquisa de novas fontes mais baratas e até a antecipação do volume obrigatório de adição de biodiesel são soluções discutidas neste ano. ${ }^{31}$

\section{Conclusões}

Os resultados serão organizados em tópicos, a fim de permitir uma revisão de todo o conteúdo do trabalho e elaborar propostas para discussão:

a) O sistema constitucional brasileiro estabeleceu o direito ao meio ambiente ecologicamente equilibrado como direito fundamental garantido pelo Estado, que informa a ordem econômica e afirma a ordem social. A partir desta relação, o incentivo ao particular a adaptar-se ao conceito constitucional de desenvolvimento sustentável tornou-se uma obrigação do Estado. Visto que o desenvolvimento social da população faz parte do conceito de desenvolvimento sustentável, é perfeitamente possível vincular os incentivos destinados aos particulares a medidas de inclusão social;

b) O modelo de política pública voltada ao desenvolvimento sustentável deve seguir algumas regras, para que possa alcançar os objetivos propostos. A partir da política nacional de produção e uso de biodiesel, deve ser observada a necessidade de equalização do custo social da política, assim como uma rígida observação da legislação ambiental aplicada ao tema e a promoção de um contexto social, político e econômico propício ao desenvolvimento do programa.

população de abelhas em uma localidade (diminuição da polinização e da produtividade dos produtores locais). Determina que a regulação ou política pública deva conjugar tanto a compensação do custo social da atividade quanto a absorção destas medidas pelos cidadãos, ou seja, até quanto estes estarão dispostos a pagar pelo incremento de custos produzido pelas regras regulatórias/políticas públicas (BREYER. Regulation and its reform, p. 23).

${ }^{31}$ Essa última medida teria como objetivo o aumento da demanda e a redução da ociosidade da rede produtora, que teria capacidade para a fabricação de 3,7 bi. de litros de biodiesel (PREÇO do petróleo em baixa ameaça biodiesel. Gazeta Mercantil. Finanças \& Mercados, p. 10. Disponível em: < http://indexet.gazetamercantil. com.br/arquivo/2009/01/05/450/Preco-do-petroleo-em-baixa-ameaca-biodiesel.html>). 


\title{
The Brazilian Biodiesel Oil Use Politics - Law as an Instrument of Social and Sustainable Development
}

\begin{abstract}
This work tries to demonstrate how Law can determine the current environmental politics in order to guide economical activities and provide a better life quality for the population. The studies are based on standards picked in the Brazilian politics of biodiesel use. These issues bring up several topics of the relationship between Law and environmental protection. It reveals that the Law system must be headed towards the assembly of a viable economical, political and social system context that makes possible a new rationality of development. Besides that, must be constructed a whole culture of effectiveness of the created rules.
\end{abstract}

Keywords: Law. Energy. Social development. Sustainability.

\section{Referências}

ABIOVE. Complexo soja: evolução das cotações médias. Disponível em: <http:// www.abiove.com.br/cotacoes_br.html>.

BBC. GE doubles spend on green agenda. Disponível em: < http://news.bbc.co.uk/2/hi/business/ 4531325.stm>.

BBC. Sci/Tec Green energy boost. Disponível em: < http://news.bbc.co.uk/2/hi/science/nature/ 307463.stm>.

BRASIL. ANP. Capacidade autorizada de plantas de produção de biodiesel. Disponível em: < http:/ /www.ibge.gov.br/home/estatistica/economia/pamclo/2007/default.shtm>.

BRASIL. ANP. Leilões de biodiesel. Disponível em: < http://www.anp.gov.br/biocombustiveis/ leilao_biodiesel.asp $>$.

BRASIL. ANP. Quinto leilão de biodiesel da ANP será dia 13 de fevereiro. Disponível em: <http://www.anp.gov.br/conheca/noticias_int.asp?intCodNoticia=208/>.

BRASIL. ANP. Relatório de importação e exportação de petróleo. Disponível em: <http:// www.anp.gov.br/doc/dados_estatisticos/Importacoes_e_Exportacoes_m3.xls>.

BRASIL. ANP. Relatório de produção de biodiesel puro (B100). Disponível em: < http:// www.anp.gov.br/doc/dados_estatisticos/Producao_de_biodiesel_m3.xls $>$.

BRASIL. ANP. Relatório de venda de combustíveis. Disponível em: < http://www.anp.gov.br/ doc/dados_estatisticos/Vendas_de_Combustiveis_m3.xls $>$.

BRASIL. Ecodiesel tem terceiro prejuízo trimestral seguido. Gazeta Mercantil. Caderno C, p. 12. Disponível em: <http://indexet.gazetamercantil.com.br/arquivo/2008/08/18/71/ Brasil-Ecodiesel-tem-terceiro-prejuizo-trimestral-seguido.html>.

BRASIL. Grupo de trabalho interministerial: biodiesel relatório final. Disponível em: <http:/ /www.biodiesel.gov.br/docs/relatoriofinal.pdf>.

BRASIL. IBGE. Produção da pecuária municipal 2006. Disponível em: <http:// www.ibge.gov.br/home/estatistica/economia/ppm/2006/ppm2006.pdf>.

BRASIL. IBGE. Sistema IBGE de recuperação automática - SIDRA. Disponível em: < http:// www.sidra.ibge.gov.br>. 
BRASIL. INPE. Projeto PRODES: monitoramento da floresta amazônica brasileira por satélite. Disponível em: <http://www.obt.inpe.br/prodes/index.html>.

BRASIL. MDA. SAF. Produtores de biodiesel com selo combustível social. Disponível em: < http:/ /www.mda.gov.br/saf/arquivos/0838818258.xls>.

BRASIL. MIR. Plano Amazônia sustentável. Disponível em: < http://www.integracao.gov.br/ pdf/desenvolvimentoregional/pas.zip >.

BREYER, Stephen. Regulation and its reform. EUA: Harvard Press University, 1982.

CHAGAS, Ana Paula. O standard do custo economicamente aceitável em direito ambiental internacional e comunitário. Revista de Direito Ambiental, São Paulo, v. 49, p. 27-53, 2007.

DERANI, Cristiane. Direito ambiental econômico. 2. ed. rev. São Paulo: Max Limonad, 2001.

EMBRAPA. Soja em números. Disponível em: < http://www.cnpso.embrapa.br/index.php? cod_pai $=16 \&$ cop_page $=294>$.

FRIEDMAN, David. Direito e ciência econômica. Sub Judice, Lisboa, n. 2, p. 31-39, 2007.

GLASMEIER, Amy K.; FARRIGAN, Tracey L. Poverty, Sustainability, and the Culture of Despair: Can Sustainable Development Strategies Support Poverty Alleviation in America's Most Environmentally Challenged Communities?. The Annals of the American Academy of Political and Social Science. Rethinking Sustainable Development, v. 590, n. 1, p. 131-149, 2003.

KAGAN, Robert A.; THORNTON, Dorothy; GUINNINGHAM, Neil. Explaining Corporate Environmental Performance: How Does Regulation Matter?. Law E Society Review, v. 37, n. 1, p. 50-89, Mar. 2003.

MACHADO, Paulo Afonso Leme. Direito ambiental brasileiro. 14. ed. rev. atual. São Paulo: Malheiros, 2006.

MILARÉ, Édis. Direito do ambiente: a gestão ambiental em foco. 5. ed. rev., atual. e ampl. São Paulo: Revista dos Tribunais, 2007.

NAPOLITANO, Ângela Aparecida. Relações entre o direito ambiental e o direito econômico. Revista de Direitos Difusos - Direito Econômico e Meio Ambiente, São Paulo, v. 24, p. 3359-3368, mar./abr. 2004.

OPENCRS. Renewable Energy Policy in the 2008 Farm Bill. Disponível em: < http:// opencrs.com/document/RL34130>.

PETROBRÁS pára de produzir H-BIO. Estadão [on line], 31 ago. 2007. Caderno Economia. Disponível em: < http://www.estadao.com.br/economia/not_eco44181,0.htm>.

PREÇO do petróleo em baixa ameaça biodiesel. Gazeta Mercantil. Finanças \& Mercados, p. 10. Disponível em: < http://indexet.gazetamercantil.com.br/arquivo/2009/01/05/450/ Preco-do-petroleo-em-baixa-ameaca-biodiesel.html>.

PROJETO busca combustível a partir do bagaço de cana. Gazeta Mercantil. Disponível em: <http://indexet.gazetamercantil.com.br/arquivo/2005/11/28/314/Projeto-buscacombustivel-a-partir-do-bagaco-de-cana.html>.

REUTERS. Petroleum daily cotation. Disponível em: < http://www.reuters.com>.

REUTERS. Soybean daily cotation. Disponível em: <http://www.reuters.com>. 
SILVA, José Afonso da. Curso de direito constitucional positivo. 28. ed. rev. e atual. São Paulo: Malheiros, 2007.

SILVA, Solange Teles da. Direito fundamental ao meio ambiente ecologicamente equilibrado. Revista de Direito Ambiental, São Paulo, v. 48, p. 225-245, 2007.

SILVA, Vasco Pereira da. Verde cor de direito: lições de direito do ambiente. Coimbra: Almedina, 2002.

VARGAS, José Israel. Energia como fator limite para o desenvolvimento sustentável. Estudos Avançados, São Paulo, n. 27, p. 295-306, 2003.

WORLD WIDE FUND FOR NATURE - WWF. Living Planet 2008 Report. Disponível em: $<$ http://www.wwf.org.uk/news_feed.cfm?uNewsID=2294>.

Informação bibliográfica deste texto, conforme a NBR 6023:2002 da Associação Brasileira de Normas Técnicas (ABNT):

BARROS FILHO, Fernando do Rego. A política nacional de uso de biodiesel: o direito como instrumento de promoção do desenvolvimento sustentável. A\&C - Revista de Direito Administrativo e Constitucional, Belo Horizonte, ano 9, n. 35, p. 171-193, jan./mar. 2009.

Recebido em: 18.01.09

Aprovado em: 06.03.09 